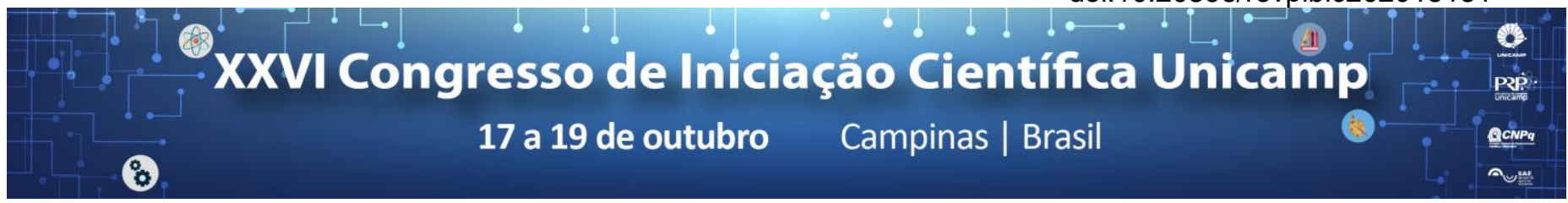

\title{
Efeito de aula dialogada e quiz no aprendizado sobre fisiologia da secreção salivar
}

\section{Bárbara Almeida*, Fernanda Klein Marcondes.}

\section{Resumo}

O uso de metodologias ativas no aprendizado tem sido comumente utilizado, para que os alunos consigam interagir ativamente com o processo de ensino-aprendizagem, diferente do modo que acontece quando são ministradas apenas aulas teóricas tradicionais, nas quais os alunos recebem a informação passivamente. Neste trabalho, tivemos a intenção de avaliar o efeito das metodologias ativas, aula dialogada e quiz, sobre o aprendizado de alunos do primeiro ano de graduação em odontologia, sobre a fisiologia da secreção salivar.

\section{Palavras-chave:}

metodologias ativas, quiz, ensino.

\section{Introdução}

Metodologias ativas de ensino podem aumentar o interesse dos alunos, sua participação em sala de aula, e seu aprendizado. Neste estudo, foram analisadas questões de prova sobre fisiologia da secreção salivar, de alunos da disciplina Cárie II $(n=301)$, do curso de graduação em odontologia, de anos em que foram aplicadas as metodologias ativas, aula dialogada e quiz, e de outros em que foram ministradas aulas teóricas. Além da análise das notas, foi analisado o tipo de erro observado.

\section{Resultados e Discussão}

Não houve diferença significativa entre a nota das provas dos alunos que assistiram aula teórica em comparação com aqueles que tiveram aula dialogada e responderam a um quiz (Tabela 1; $p>0,05$ ).

Porém observou-se que a porcentagem de alunos que obtiveram notas acima de 5 e 7 foi maior no grupo em que a aula dialogada foi utilizada, em comparação com o grupo em que foi ministrada a aula teórica tradicional (Figura 1).

Com relação às respostas referentes aos efeitos diretos e vasculares do Sistema Nervoso Autônomo sobre a secreção salivar, apenas $23,07 \%$ dos alunos explicaram corretamente os efeitos diretos e vasculares dos mediadores autonômicos sobre a secreção salivar. No grupo em que o assunto foi ministrado com aulas dialogadas, esta porcentagem aumentou para $32,30 \%$, indicando uma maior compreensão do assunto após aula dialogada.

Tabela 1. Média aritmética das notas dos alunos em questão de prova sobre secreção salivar.

\begin{tabular}{cc}
\hline \hline Grupos & Média \pm Desvio Padrão \\
\hline \hline Grupo Metodologia Ativa & $4,30 \pm 2,34$ \\
Grupo Aula Tradicional & $4,67 \pm 2,34$ \\
\hline \hline
\end{tabular}

Figura 1. Comparação da porcentagem de alunos com notas >5 e >7 na utilização de metodologias-ativas e aulas tradicionais.

Porcentagem de alunos com nota acima de 7,0

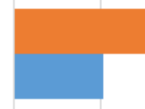

Porcentagem de alunos com nota acima de 5,0

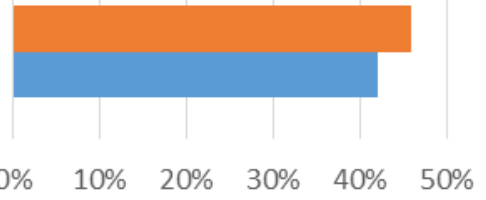

Metodologias-ativas aulas tradicionais

\section{Conclusão}

Os dados obtidos no presente estudo indicam que as metodologias ativas avaliadas parecem contribuir para o sucesso do processo ensino-aprendizagem sobre os mecanismos fisiológicos da secreção salivar, indicando que tornar os alunos ativos durante as aulas, pode resultar em melhor rendimento e compreensão do tema estudado.

\section{Agradecimentos}

\section{QCNPq Bolsa PIBIC/UNICAMP}

TFapesp projeto temático 2011/50419-2

2017 Teaching Career Enhancement Award 